\title{
EDITORIAL
}

\section{The growing role of citizen science in monitoring environmental change - achieving a balance with government programs? ${ }^{1}$}

The evidence is becoming clearer, day by day, that changes are occurring at the global level in weather, climate, the oceans, land use and population distribution, all of which have serious implications for natural ecosystems and their inhabitants, in Canada and beyond. At the same time, government (public service) programs in recent years involving long term monitoring of the Canadian environment have been drastically reduced. This has affected our ability to detect spatial and temporal changes in a range of indicators, thereby inhibiting the ability of policy and decision makers to respond in a timely way to environmental changes. For example, Canada's exemplary Environmental Monitoring and Assessment Network (EMAN) that initiated Nature Watch, a national citizen science monitoring program (www. ec.gc.ca), ceased operation in 2010; its last regional workshop was held in 2006. Many EMAN-linked programs, in and out of government, have either stopped due to loss of funding and staff, or are just struggling to survive. Although a change in the federal government may reverse the pattern and essential monitoring may eventually resume in earnest, valuable data and information for recent years have been lost forever.

This situation highlights the pivotal role of citizen science, particularly when it is directed at monitoring the various natural environments in Canada and in our region. Such activity by non-government organizations (NGOs) is no longer just a valued supplement to government sponsored programs; in many cases, it has replaced them. However, this situation raises some questions, to be pondered by members of NSIS and the broad environmental community- is this trend towards an enhanced role for citizen science good for the country? How reliable are data and information gathered by citizen groups? Where do such data reside? Who writes and reviews the various reports? Who curates and archives the data and information? How long can citizen

1 This article celebrates the 40th Anniversary of the Halifax Field Naturalists, founded in 1975. A description of its activities, together with its excellent Newsletters, can be found at www.halifaxfieldnaturalists.ca . 
groups continue and under what funding envelope (i.e., some monitoring, such as for water quality and chemicals in sediments and tissues, is very expensive)? If there is going to be greater reliance on citizen science, such fundamental questions demand credible answers!

The respected role of citizen-led science has been shown particularly well by programs such as the Christmas Bird Count across Canada and the USA, and in Nova Scotia with the Spring Peeper Count and the Kejimkujik Common Loon Survey. In Halifax, there is the monthly reporting of anecdotal observations of plants, wildlife, and habitats, as well as related talks, by the Halifax Field Naturalists (HFN); this society, affiliated with Nature Canada and Nature Nova Scotia, is celebrating its 40th anniversary in 2015, a truly remarkable achievement. Bird populations, a key indicator of general ecosystem health, are monitored by the Nova Scotia Bird Society. Both of these local groups keep records. Of a more general nature is the annual Clean Nova Scotia beach clean-up and recording of marine litter, the Clean Annapolis River Project water quality program in the Annapolis River watershed, water quality monitoring in the Sackville and Cornwallis River watersheds, and many others. Such programs produce much information and also play a vital role in public education and awareness. But they do have limitations, as they are run by volunteers and specific programs may be short-term. Although there are exceptions, the data collected rarely follow standard management protocols and are seldom if ever housed in a central location. Reports are often placed on group websites, but with little assurance of longevity, access, and security. Indeed, funding challenges often limit or stop these groups and their programs in midstream. In contrast to government (public service) science, there is no formal mandate other than public interest, volunteerism and commitment to a worthy cause to maintain many of these citizen led science programs.

Ironically, despite such disadvantages, the importance of citizen-led science programs has been widely recognized, partly because many government-led and legally mandated programs have been reduced or eliminated. Our premise is that in an affluent country like Canada, with its continental and global environmental responsibilities, we need a balance between such citizen science programs, especially those monitoring aspects of the environment, and programs established and run by government. They are both needed. We believe that our challenge at present is to return to this balance. 
A significant number of federal science and monitoring programs have been eliminated since 2011-2012 (e.g., the Arctic ozone monitoring program, the Experimental Lakes Area Program, ecotoxicology of pesticides related to marine open-water aquaculture sites) or continue with severe underfunding (e.g., the Gulf of Maine Council's, Gulfwatch contaminant monitoring program). Furthermore, whole research programs associated with understanding and mitigating the effects of chemicals in aquatic environments have ceased (e.g., the Department of Fisheries and Oceans, environmental chemistry and aquatic toxicology program; many similar programs in Environment Canada). At the same time, NGOs struggle for project funding and universities seldom become involved in environmental monitoring (with some marked exceptions, such as the Ocean Tracking Network program at Dalhousie University, the St John River studies at the Canada Rivers Institute, UNB-Saint John and the Community Conservation Research Network at Saint Mary's University, Halifax). The evidence points to too little long term monitoring of Canada's many ecosystems, a legislated mandate of government.

Despite the many good examples of citizen science across the Maritimes, the frequent lack of support for their organizations, combined with the cutbacks of government (both federal and provincial), do not bode well for understanding the current and future consequences of environmental threats in Canada and in the Maritimes. Public debate is needed around this issue. The NSIS, members of relevant NGOs, government departments at all levels, and the universities should get together to discuss the best ways to monitor natural ecosystems in our Region, and provide cogent arguments to bolster the long-term viability of NGOs and to counteract the troubling trends of cutbacks in public service programs. We need to identify how citizen science and government science, supported by research in the universities, can work together, as well as interact with policymakers, for a better future in a changing environment.

Peter G. Wells and David H. S. Richardson, Editor and Associate Editor, PNSIS 
